\title{
Reconciling tracer and float observations of the export pathways of Labrador Sea Water
}

\author{
S. F. Gary, ${ }^{1}$ M. S. Lozier, ${ }^{1}$ A. Biastoch, ${ }^{2}$ and C. W. Böning ${ }^{2}$ \\ Received 25 September 2012; revised 8 November 2012; accepted 10 November 2012; published 22 December 2012.
}

[1] For more than fifty years, it has been generally accepted by oceanographers that the Deep Western Boundary Current (DWBC) is the principal conduit of recently-convected Labrador Sea Water (LSW) exported from the high-latitude North Atlantic to the equator. Supporting this supposition is observational evidence that the waters of the DWBC have consistently greater equatorward velocities, higher concentrations of passive tracers, and younger ages compared to ocean interior waters. However, recent observations and simulations of floats launched in the DWBC in the Labrador Sea show that most water parcels are quickly ejected from the DWBC and follow instead interior pathways to the subtropics. Here, we show that tracer observations from the last three decades are compatible with the existence of both DWBC and basininterior export pathways. From analyses of observational data and model output, we find that equatorward transport in the basin interior is consistent with the large-scale vorticity balance at mid-depth. Furthermore, from the modeling analysis we show that despite higher, localized concentrations of tracer and particles in the DWBC, only 5\% of particles released in the Labrador Sea are transported from the subpolar to subtropical gyre via a continuous DWBC pathway. Thus, the interior pathway is a significant contributor to LSW export. Citation: Gary, S. F., M. S. Lozier, A. Biastoch, and C. W. Böning (2012), Reconciling tracer and float observations of the export pathways of Labrador Sea Water, Geophys. Res. Lett., 39, L24606, doi:10.1029/2012GL053978.

\section{Introduction}

[2] Atmospheric gases are mixed into the high-latitude surface waters which are brought to depth by wintertime convection and then transported equatorward, through the North Atlantic [Doney and Jenkins, 1994; Smethie, 1993; Smethie et al., 2000; Sabine et al., 2004]. The deep ocean, therefore, represents a sink of anthropogenic $\mathrm{CO}_{2}$ and chlorofluorocarbons (CFCs). Since $\mathrm{CO}_{2}$ and $\mathrm{CFCs}$ are greenhouse gases and since dissolved $\mathrm{CO}_{2}$ contributes to ocean acidification, an understanding of the mechanisms distributing these gases in the deep ocean is of interest.

[3] Until recently, the dominant paradigm describing the circulation of the deep waters of the North Atlantic was based on a first order vorticity balance [Stommel, 1958]. This

\footnotetext{
${ }^{1}$ Division of Earth and Ocean Sciences, Nicholas School of the Environment, Duke University, Durham, North Carolina, USA.

${ }^{2}$ Division of Ocean Circulation and Climate Dynamics, GEOMAR Helmholtz Centre for Ocean Research, Kiel, Germany.

Corresponding author: S. F. Gary, Division of Earth and Ocean Sciences, Nicholas School of the Environment, Duke University, Box 90227, Durham, NC 27708, USA. (stefan.gary@duke.edu)

(C)2012. American Geophysical Union. All Rights Reserved. 0094-8276/12/2012GL053978
}

balance predicts that all deep flow in the basin interior is poleward and that the only possible equatorward flow at depth is along the western boundary in the Deep Western Boundary Current (DWBC). Another explanation for the DWBC is eddies interacting with steeply sloping topography [Vallis and Maltrud, 1993]. Regardless of its driving mechanism, the DWBC has been widely viewed as the main, continuous conduit for the equatorward export of deep waters.

[4] Direct velocity measurements of the DWBC, conducted at several locations along the western boundary of the North Atlantic, confirm that velocities in the DWBC are equatorward and greater than the velocities in the basin interior [Dengler et al., 2006; Fischer et al., 2004; Lee et al., 1996; Schott et al., 2004]. Furthermore, DWBC waters contain consistently higher concentrations of CFCs than the interior, an indication that DWBC waters are closely tied to the high-latitude regions where deep convection acts to bring CFCs to depth [Doney and Jenkins, 1994; Smethie, 1993; Smethie et al., 2000].

[5] In contrast to the Eulerian observations cited above, Lagrangian observations achieved with neutrally-buoyant float trajectories show that particles launched in the DWBC are likely to exit the DWBC and transit the basin interior as they move from high to low latitudes [Bower et al., 2009; Fischer and Schott, 2002; Lavender et al., 2000; Bower and Hunt, 2000].

[6] The central question of this paper stems from the apparent contradictory views of the deep circulation in the North Atlantic as revealed by tracer and float observations: Are recently ventilated waters exported to low latitudes along a dominant DWBC pathway, as suggested by high CFC concentrations in the boundary current, or does the DWBC coexist with significant interior pathways, as suggested by float observations?

\section{Data Sources and Processing}

\subsection{Observations}

[7] CFC-11 observations are from the CARINA V1.0 [CARINA Group, 2009] and GLODAP V1.0 [Key et al., 2004] databases. Cruises that are not in CARINA and GLODAP, but are in WOD09 [National Oceanographic Data Center, 2010], were also included in our database. We included data from Transient Tracers in the Ocean North Atlantic Sector (TTO-NAS) Leg 7 cruise (J. Bullister and T. Tanhua, personal communication, 2010) and Line $\mathrm{W}$ [Toole et al., 2011]. Finally, we use the updated hydrographic database of Gary et al. [2011] including all bottle, CTD, and Argo hydrographic data in WOD09 [National Oceanographic Data Center, 2010] up to 2011. A climatology was constructed from this database with Hydrobase2 [Lozier et al., 1995; Curry, 2010]. 

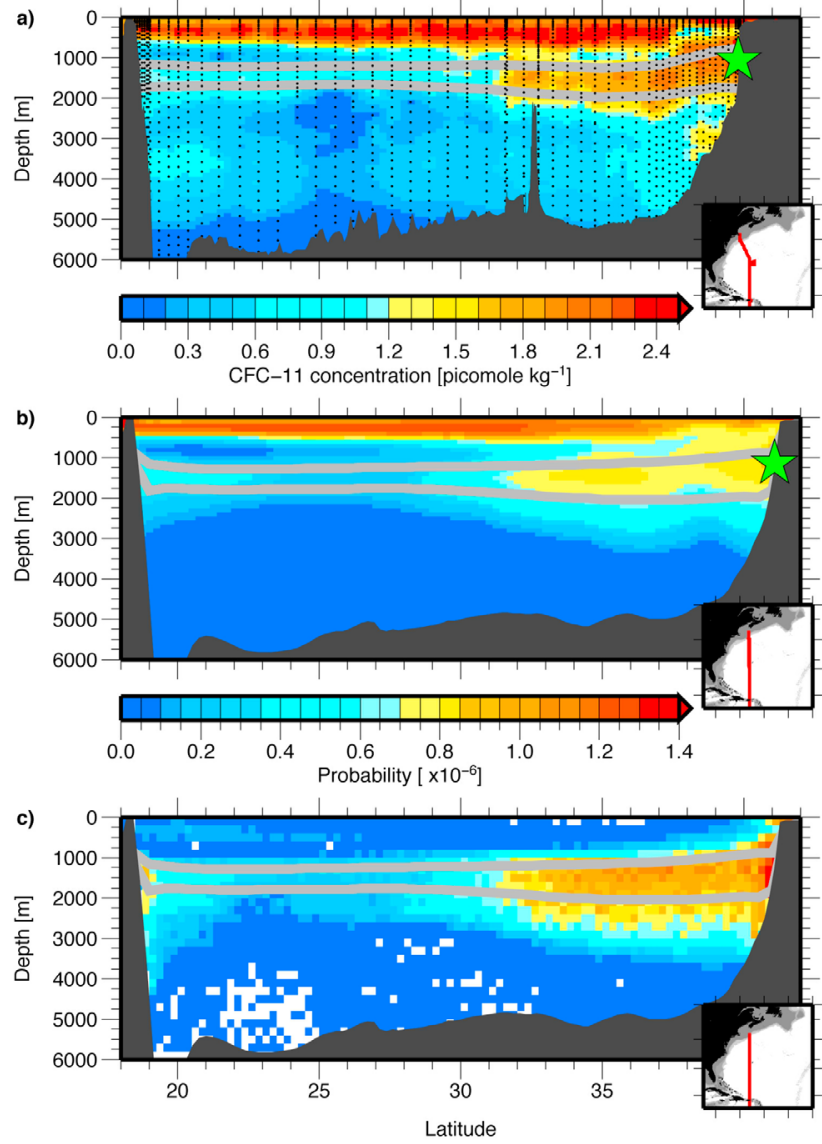

Figure 1. Observed and modeled CFC-11 concentrations and particle position probability near $66^{\circ} \mathrm{W}$. (a) CFC-11 concentrations measured along R/V Knorr cruise 316 from 10/24/ 2003 to 11/12/2003. (b) November 2003 mean CFC-11 concentration from ORCA025. Green stars are the instantaneous locations of the DWBC CFC core. (c) Particle position probability computed from 609,055 simulated particles launched at the surface of the Labrador Sea in ORCA025. Gray lines are the average locations of the $\sigma_{\theta}=27.68$ and $27.80 \mathrm{~kg} \mathrm{~m}^{-3}$ isopycnals (the characteristic LSW density range) from the hydrographic climatology (Figure 1a) or from the model (Figures 1b and 1c). Inset maps show section locations.

\subsection{Model and Simulated Lagrangian Trajectories}

[8] The model used in this study is the ORCA025 global, $1 / 4^{\circ}$ eddy-permitting resolution, general circulation model [Barnier et al., 2006; DRAKKAR Group, 2007]. This particular model run is a 1958 to 2004 hindcast and is described in more detail by Gary et al. [2011]. The strength and variability of the ORCA025 DWBC, all along the boundary, is similar to observed values.

[9] For the ORCA025 tracer simulation, velocity and diffusivity fields at every integration time step were used to update temperature, salinity, and CFC-11 fields. Identical operators and parameterizations were applied to all tracers. There was no CFC-11 during the first year of the simulation, 1958 , to allow the model to reach an initial geostrophic balance after the shock from the initial conditions. For 1959 to 2004, the ocean surface took up CFC-11 [Lachkar et al., 2007] and monthly mean tracer distributions were saved.
[10] Three-dimensional particle trajectories are computed offline with ORCA025 5-day average velocity fields [Gary et al., 2011; Blanke and Grima, 2010]. Particles are launched every ten days from 1980 to 2004 at the Labrador Sea surface between $62^{\circ} \mathrm{W}$ to $48^{\circ} \mathrm{W}$ and $53^{\circ} \mathrm{N}$ to $65^{\circ} \mathrm{N}$ with temperatures between $3.0^{\circ} \mathrm{C}$ and $4.0^{\circ} \mathrm{C}$, generating 609,055 trajectories. Float positions, at 30 -day intervals, are calculated for 50 years by cycling through the 1980-2004 velocity fields with a temporal discontinuity at Dec 31, 2004 to Jan 1, 1980.

[11] Particle position probability volumes are constructed by subdividing the North Atlantic into $0.25^{\circ}$ by $0.25^{\circ}$ by $200 \mathrm{~m}$ boxes, counting the number of times particles are present in each box, including repetitions, and dividing by the number of particle positions. Different bin sizes $\left(0.1^{\circ}\right.$ to $1^{\circ}$ horizontally, 50 to $500 \mathrm{~m}$ vertically) generate similar results. Since we compute probabilities using full length trajectories, probabilities reflect the integrated effect of the passage of particles over the simulation duration. Therefore, probability volumes constructed from 50-year trajectories are comparable to CFC concentrations measured decades after the start of tracer accumulation.

\section{Tracers in the Boundary and Interior}

[12] A representative section of CFC concentrations in the North Atlantic (Figure 1a) reveals high concentrations near the surface and a local maximum centered at $1000 \mathrm{~m}$. This mid-depth maximum is associated with LSW that was brought to depth in the Labrador Sea during winter convection [Smethie et al., 2000; Smethie, 1993]. This CFC signature is aligned with the LSW density range $\sigma_{\theta}=27.68$ to $27.80 \mathrm{~kg} \mathrm{~m}^{-3}$ [Dengler et al., 2006]. A smaller, deeper, local maximum of CFC, centered at $3000 \mathrm{~m}$, is attributed to dense overflow waters originating in the Norwegian and Greenland Seas [Smethie et al., 2000; Smethie, 1993]. The highest CFC concentration below the surface layer (green star, Figure 1a) is against the continental slope and resides in the upper portion of the DWBC. There is also a significant amount of tracer in the interior in addition to the DWBC.

[13] The mid-depth, high CFC concentration core in the DWBC is reproduced in the CFC simulation within ORCA025. As in observations, the model exhibits elevated levels of CFC in the interior and a strong CFC signal along the boundary. The lower CFC concentrations in ORCA025 reflect the fact that CFC was added to the simulation after January 1, 1959, while the real ocean has been taking up small amounts of CFC since the $1930 \mathrm{~s}$.

[14] One feature of the observed CFC distribution that is not reproduced by the model is the weaker, deeper core of CFC concentrations associated with the overflow waters. ORCA025 uses a partial step representation of bathymetry and a bottom boundary layer parameterization. This combination, while generally advantageous, does not adequately resolve overflow plumes. In case of overflow waters, additional mixing erases the tracer signal [Griffies et al., 2005]. However, CFC in LSW is not significantly altered by this effect because LSW resides at intermediate depths.

[15] We define the DWBC CFC core as the highest CFC-11 concentration below $500 \mathrm{~m}$ and inshore of the $4000 \mathrm{~m}$ isobath, the latter an estimate of the offshore edge of the DWBC since absolute velocity observations are not always available. The sorting of DWBC CFC observations by distance along the western boundary and date reveals a DWBC tracer core that appears to propagate continuously and steadily equatorward 
(Figure 2a). In contrast, the DWBC tracer core in the model exhibits a discontinuity near the Tail of the Grand Banks (TGB) (Figure 2b). However, when the model CFC fields are subsampled at the approximate location and date of each observation, the discontinuity at TGB is no longer resolved (Figure 2c). Therefore, we surmise that the steady progression of the observed tracer signal in the DWBC is likely an artifact of limited observations.

[16] The discontinuity of the tracer signal at the TGB (Figure 2b), at the approximate boundary between the subpolar and subtropical gyres, is located where observations and simulations in ORCA025 and other models [Bower et al., 2009; Gary et al., 2011] show that Lagrangian particles are ejected from the DWBC. While strong advective pulses of CFC in the mid to late 1990s, present in the model (Figure 2b) and suggested by observations (Figure 2a), likely reflect intense LSW production in the early 1990s, these pulses extend to only a few $1000 \mathrm{~km}$ along the boundary and are intermittent. Though the loss of tracer is maximized in the vicinity of the TGB, it occurs along the whole western boundary, consistent with the well-known discrepancy between observed tracer signal propagation rates $\left(1 \mathrm{~cm} \mathrm{~s}^{-1}\right)$ and observations of pure advection in the DWBC $\left(10 \mathrm{~cm} \mathrm{~s}^{-1}\right)$ [Smethie et al., 2000; Doney and Jenkins, 1994; Bower and Hunt, 2000].

\section{Lagrangian Pathways of LSW}

[17] To understand differences between the distribution of LSW described by these tracer fields, modified by advection and diffusion (Figures 1a and 1b), and that described by Lagrangian pathways, which provide a purely advective view, we compute trajectories of $6.1 \times 10^{5}$ particles launched at the surface of the Labrador Sea in ORCA025, construct a particle position probability volume from the resulting trajectory ensemble, and compare the probabilities to simulated and observed tracer fields. The comparison is quite favorable: the greatest particle probabilities are in the DWBC (Figure 1c), coincident with the highest tracer concentrations (Figures 1a and 1b). These probabilities decrease, as do tracer concentrations, toward the interior. The favorable comparison suggests that the observed and modeled tracer signal is generally dominated by advection. As such, our interpretation of the tracer field should not markedly deviate from our interpretation of particle pathways. We do, however, note one difference: the relatively high particle probabilities at $19^{\circ} \mathrm{N}$ coincide with only a weak local tracer concentration maximum, a difference attributed to the accumulated impact of small scale diffusion a long distance away from the LSW source region. Overall, we note from this comparison that although there is a strong probability and tracer signal at the boundary, many particles and much tracer reside in the basin interior.

[18] A qualitative comparison of the spreading of tracer and particles is presented in the accompanying animation of simulated tracer and particle column inventories (Animation S1 in the auxiliary material). ${ }^{1}$ At the beginning of the animation, particles and tracer move from the Labrador Sea into the Irminger Sea, Newfoundland Basin, and Eastern Atlantic: the three traditionally accepted pathways for LSW [Talley and

${ }^{1}$ Auxiliary materials are available in the HTML. doi:10.1029/ 2012GL053978.
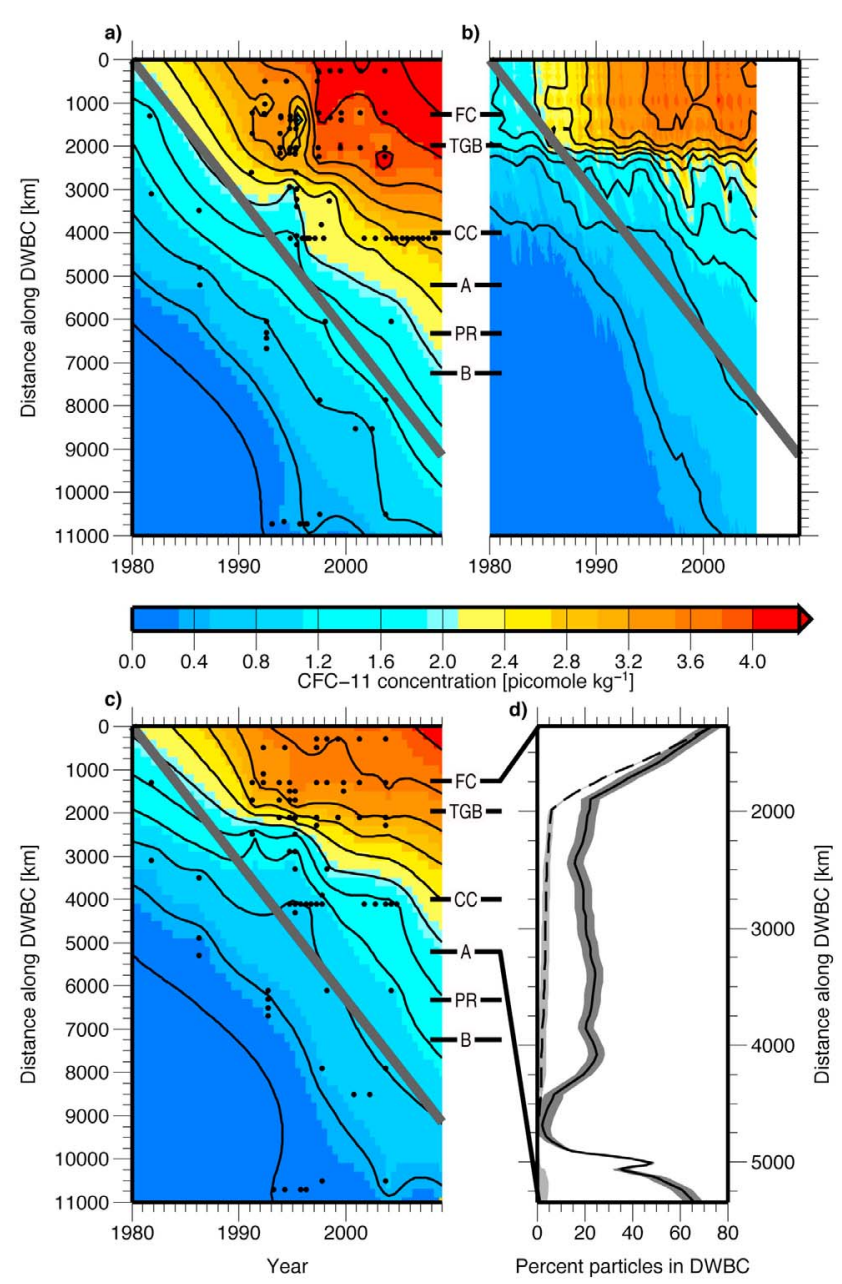

Figure 2. Spreading rates of the CFC-11 signal in the DWBC. (a) Magnitude of the DWBC CFC core at each observed section of the DWBC. The shaded and contoured field is interpolated [Smith and Wessel, 1990] between observations (black dots) onto a $200 \mathrm{~km}$ by 6 -month resolution grid. Each dot is a CFC-11 maximum in the DWBC. (b) Magnitude of the DWBC CFC core in ORCA025. Black contour lines at 0.4 picomole $\mathrm{kg}^{-1}$ intervals represent a smoothed version of the color shaded background at the same resolution as Figure 2a. (c) Magnitude of the DWBC CFC core in ORCA025 output that has been subsampled at the approximate time and place of the observations (black dots). The surrounding values are determined by interpolation as in Figure 2a. (d) Percent of particle first arrival positions from $48^{\circ} \mathrm{N}$ to $25^{\circ} \mathrm{N}$ in the DWBC, defined by being inshore of the $4000 \mathrm{~m}$ isobath. The dashed line represents particles that are continuously inshore starting from $48^{\circ} \mathrm{N}$. The solid line is an inventory of all particles that go into the DWBC. Two standard deviation envelopes, constructed from 1000 iterations of 500 random trajectory subsamples of the ensemble, are shaded around each line. The distance along the boundary starts at $0 \mathrm{~km}$ at $55^{\circ} \mathrm{N}$ on the western boundary of the Labrador Sea and geography is indicated by FC (Flemish Cap), TGB (Tail of the Grand Banks), CC (Cape Cod), A (Abaco), PR (Puerto Rico), and B (Barbados). Gray lines represent a slope of $1 \mathrm{~cm} \mathrm{~s}^{-1}$. 

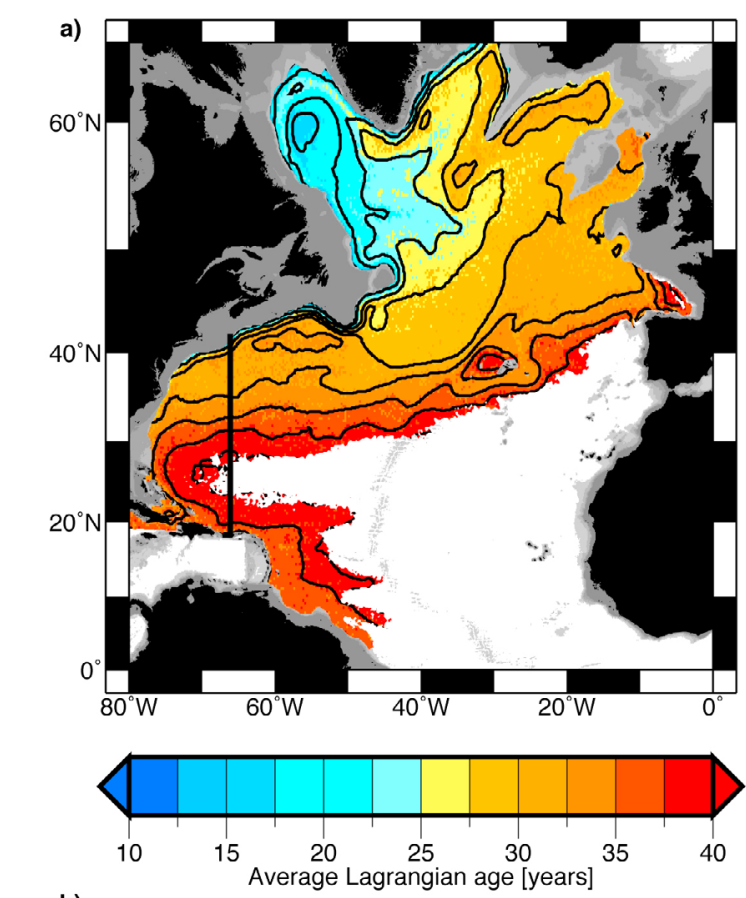

b)

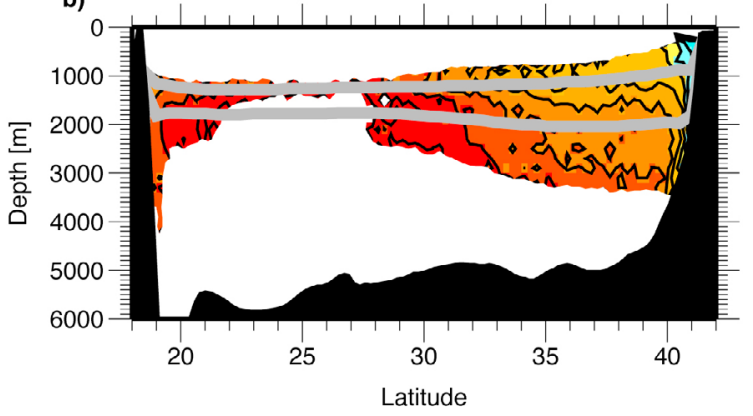

Figure 3. Lagrangian age of simulated LSW. (a) Average particle age at $1500 \mathrm{~m}$. (b) Vertical section of average age at $66^{\circ} \mathrm{W}$. Blank regions experienced less than 100 particle visits over 50 years. Black lines on maps are section locations. Gray lines on sections are the average location of the $\sigma_{\theta}=27.68$ and $27.80 \mathrm{~kg} \mathrm{~m}^{-3}$ isopycnals in ORCA025 from 1980 to 2004, as in Figure 1.

McCartney, 1982]. After several years have passed in the animation, the export of LSW from the subpolar to subtropical gyres is visible in both the DWBC and the interior.

[19] The relative importance of the DWBC and interior export pathways is quantified by inventories of simulated particles in the DWBC (Figure 2d) [Bower et al., 2009]. We define the boundary between the interior and the DWBC as the $4000 \mathrm{~m}$ isobath. Since our focus is the export of LSW, only trajectories of the $5.3 \times 10^{4}$ particles that crossed $25^{\circ} \mathrm{N}$ within 50 years and never went onto the continental shelf are used for this calculation. Furthermore, our inventory only includes particle first arrival positions at each $0.5^{\circ}$ bin in the DWBC. Any recirculation is ignored. Although $75 \%$ of the particles cross $48^{\circ} \mathrm{N}$ in the DWBC, they are quickly ejected from the DWBC as noted above. Most particles in the DWBC have strayed into the interior and less than $5 \%$ of particles follow a direct and continuous pathway along the boundary. Even including the particles exchanged between the DWBC and the interior, only $\sim 25 \%$ reside in the DWBC at each location between $44^{\circ} \mathrm{N}$ and $30^{\circ} \mathrm{N}$. South of $26^{\circ} \mathrm{N}$, $65 \%$ of the particles have rejoined the DWBC.

[20] Lagrangian data also allow for the quantification of particle spreading time scales. We calculate Lagrangian age by averaging the particle transit times reaching each $0.25^{\circ}$ by $0.25^{\circ}$ by $200 \mathrm{~m}$ box in the North Atlantic. The ages constructed from our simulation (Figures $3 a$ and $3 b$ ) are similar to ages from tracer observations at the depth of LSW [Smethie et al., 2000; Fine et al., 2002]. The DWBC is clearly the fastest LSW export pathway to the subtropics (Figures 3a and $3 b$ ).

\section{Vorticity Balance in the Interior}

[21] Finally, we test if the observed equatorward movement of LSW in the basin interior [Bower et al., 2009] is consistent with large-scale dynamical theory using the first order vorticity balance between water column stretching and planetary vorticity:

$$
\beta v=-f \nabla_{H} \cdot \mathbf{u}
$$

where $f$ is the Coriolis parameter, $\mathbf{u}=(u, v, w)$ is velocity, $\beta=\partial f / \partial y, y$ is latitude, $z$ is the vertical coordinate, and the $H$ subscript denotes the horizontal divergence in $z$-level or isopycnal coordinates [Stommel, 1958; Gary et al., 2011]. This balance applies to waters at depth isolated from baroclinic effects, forcing and dissipation. Equation (1) states that a local divergence of the horizontal flow, corresponding to water column compression, is dynamically consistent with equatorward velocity. In both observations and ORCA025, the layer thickness decreases as a particle follows an equatorward path (Figure 4). This equatorward flow, which is not necessarily purely meridional, is consistent with equation (1).

[22] Layer potential vorticity, $f / h$, where $h$ is the thickness between two isopycnals, is conserved for fluid isolated from surface forcing and/or dissipation. In the absence of eddies, we expect particles to follow contours of mean $f / h$. However,

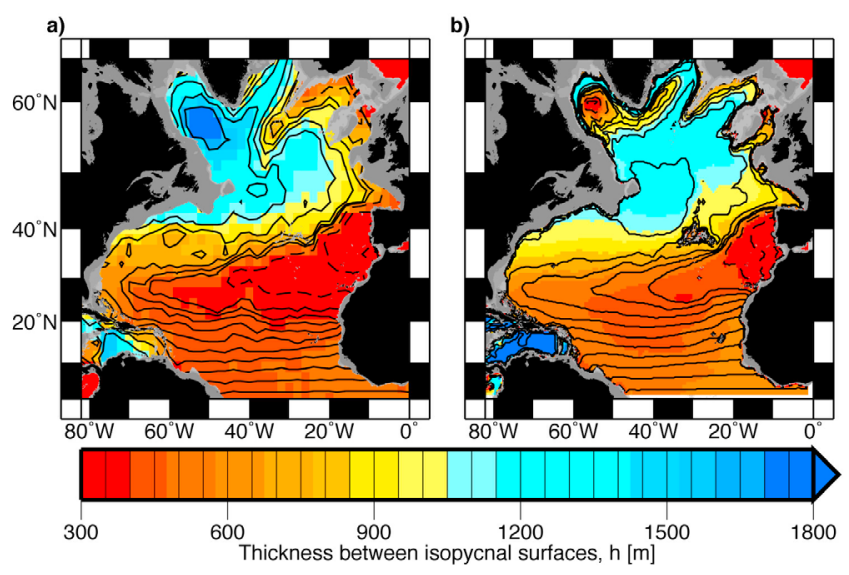

Figure 4. LSW layer thickness and potential vorticity. (a) Average thickness, $h$, between the $\sigma_{\theta}=27.68$ and $27.80 \mathrm{~kg} \mathrm{~m}^{-3}$ isopycnals from the hydrographic climatology. (b) Average thickness between the same isopycnals as in panel a but in the ORCA025 model. Average layer potential vorticity, $f / h$, for each is shown with solid (dashed) black lines at $1.5 \times 10^{-8}\left(1 \times 10^{-7}\right) \mathrm{m}^{-1} \mathrm{~s}^{-1}$ intervals (zero at the equator). 
regions of homogenized or closed contours of mean $\mathrm{f} / \mathrm{h}$ (Figure 4) are signatures of an eddy-driven mean flow across mean $f / h$ contours, allowing equatorward flow in the interior [Lozier, 1997].

[23] The large difference in Figure 4 between the observations and ORCA025 in the northern subpolar gyre is due to the ORCA025 $\sigma_{\theta}=27.80 \mathrm{~kg} \mathrm{~m}^{-3}$ isopycnal being much shallower than observations in that region. We note that the modeled $f / h$ field exhibits weaker gradients compared to the observed field in this region, suggesting that the model may overestimate the spread of LSW into the interior. However, the spread of observed float pathways in the interior are indistinguishable from that of the simulated trajectories [Gary et al., 2011].

\section{Summary and Conclusions}

[24] We have shown that ocean tracer, density, and Lagrangian observations are consistent with the export of LSW via an interior, equatorward, pathway in addition to the traditionally accepted DWBC pathway. Our simulations, in agreement with observations, show that the DWBC is on average the fastest pathway for LSW export. In the model, $\sim 75 \%$ of simulated LSW particles are transported in the interior between $44^{\circ} \mathrm{N}$ and $30^{\circ} \mathrm{N}$. Although the DWBC gradually regains most of the particles it lost by about $30^{\circ} \mathrm{N}$, fewer than $5 \%$ of particles followed a continuous path along the DWBC. These conclusions agree with other studies which show that eddy-driven deep recirculation gyres are a plausible mechanism for the existence of an interior pathway [Gary et al., 2011; Lozier, 1997] and these large-scale, interior flow patterns shape the spreading of tracer [Lozier, 1999].

[25] Acknowledgments. The authors are thankful for financial support from the US National Science Foundation and the German Academic Exchange Service (DAAD). S.F.G. is thankful to John Bullister and Toste Tanua for sharing CFC-11 data.

[26] The Editor and the authors thank two anonymous reviewers for their assistance in evaluating this paper.

\section{References}

Barnier, B., et al. (2006), Impact of partial steps and momentum advection schemes in a global ocean circulation model at eddy permitting resolution, Ocean Dyn., 56, 543-567.

Blanke, B., and N. Grima (2010), Ariane v2.2.6, technical report, Lab. de Phys. des Oceans, Plouzane, France. [Available at http://stockage.univ-brest.fr/ grima/Ariane/.]

Bower, A. S., and H. D. Hunt (2000), Lagrangian observations of the Deep Western Boundary Current in the North Atlantic Ocean Part I: Large scale pathways and spreading rates, J. Phys. Oceanogr., 30, 764-783.

Bower, A. S., M. S. Lozier, S. F. Gary, and C. W. Böning (2009), Interior pathways of the North Atlantic meridional overturning circulation, Nature, 459, 243-247.

CARINA Group (2009), Carbon in the Atlantic Ocean RegionThe CARINA project: Results and data, version 1.0, technical report, Carbon Dioxide Inf. Anal. Cent., Oak Ridge Natl. Lab., U.S. Dep. of Energy, Oak Ridge, Tenn., doi:10.3334/CDIAC/otg.CARINA.ATL.V1.0.

Curry, R. G. (2010), Hydrobase2: A global database of hydrographic profiles and tools for climatological analysis, technical report, Woods Hole
Oceanogr. Inst., Woods Hole, Mass. [Available at http://www.whoi. edu/science/PO/hydrobase/.]

Dengler, M., J. Fischer, F. A. Schott, and R. Zantopp (2006), Deep Labrador Current and its variability in 1996-2005, Geophys. Res. Lett., 33, L21S06, doi:10.1029/2006GL026702.

Doney, S. C., and W. J. Jenkins (1994), Ventilation of the Deep Western Boundary Current and abyssal western North Atlantic: Estimates from tritium and ${ }^{3} \mathrm{He}$ distributions, J. Phys. Oceanogr., 24, 638-659.

DRAKKAR Group (2007), Eddy-permitting ocean circulation hindcasts of the past decades, CLIVAR Exchanges, 12(42), 8-10.

Fine, R. A., M. Rhein, and C. Andrié (2002), Using a CFC effective age to estimate propagation and storage of climate anomalies in the deep western North Atlantic Ocean, Geophys. Res. Lett., 29(24), 2227, doi:10.1029/ 2002 GL015618.

Fischer, J., and F. A. Schott (2002), Labrador Sea Water tracked by profiling floats-From the boundary current to the open North Atlantic, J. Phys. Oceanogr., 32, 573-584.

Fischer, J., F. A. Schott, and M. Dengler (2004), Boundary circulation at the exit of the Labrador Sea, J. Phys. Oceanogr., 34, 1548-1570.

Gary, S. F., M. S. Lozier, C. W. Böning, and A. Biastoch (2011), Deciphering the pathways for the deep limb of the meridional overturing circulation, Deep Sea Res., Part II, 58, 1781-1797.

Griffies, S. M., et al. (2005), Formulation of an ocean model for global climate simulations, Ocean Sci. Discuss., 2, 165-246.

Key, R. M., A. Kozyr, C. L. Sabine, K. Lee, R. Wanninkhof, J. L. Bullister, R. A. Feely, F. J. Millero, C. Mordy, and T.-H. Peng (2004), A global ocean carbon climatology: Results from Global Data Analysis Project (GLODAP), Global Biogeochem. Cycles, 18, GB4031, doi:10.1029/ $2004 \mathrm{~GB} 002247$.

Lachkar, Z., J. C. Orr, J.-C. Dutay, and P. Delecluse (2007), Effects of mesoscale eddies on global ocean distributions of CFC-11, $\mathrm{CO}_{2}$ and $\delta^{14} \mathrm{C}$, Ocean Sci., 3, 461-482.

Lavender, K. L., R. E. Davis, and W. B. Owens (2000), Mid-depth recirculation observed in the interior Labrador and Irminger seas by direct velocity measurements, Nature, 407, 66-69.

Lee, T. N., W. E. Johns, R. J. Zantopp, and E. R. Fillenbaum (1996), Moored observations of western boundary current variability and thermohaline circulation at $26.5^{\circ} \mathrm{N}$ in the subtropical North Atlantic, J. Phys. Oceanogr., 26, 962-983.

Lozier, M. S. (1997), Evidence for large-scale eddy-driven gyres in the North Atlantic, Science, 277, 361-367.

Lozier, M. S. (1999), The impact of mid-depth recirculations on the distribution of tracers in the North Atlantic, Geophys. Res. Lett., 26, 219-222, doi:10.1029/1998GL900264.

Lozier, M. S., W. B. Owens, and R. G. Curry (1995), The climatology of the North Atlantic, Prog. Oceanogr., 36, 1-44.

National Oceanographic Data Center (2010), World Ocean Database Select and Search, technical report, NOAA, Silver Spring, Md. [Available at http://www.nodc.noaa.gov/OC5/SELECT/dbsearch/dbsearch.html.]

Sabine, C. L., et al. (2004), The oceanic sink for anthropogenic $\mathrm{CO}_{2}$, Science, 305, 367-371.

Schott, F. A., R. Zantopp, L. Stramma, M. Dengler, J. Fischer, and M. Wibaux (2004), Circulation and deep-water export at the western exit of the subpolar North Atlantic, J. Phys. Oceanogr., 34, 817-843.

Smethie, W. M. (1993), Tracing the thermohaline circulation in the western North Atlantic using chlorofluorocarbons, Prog. Oceanogr., 31, 51-99.

Smethie, W. M., Jr., R. A. Fine, A. Putzka, and E. P. Jones (2000), Tracing the flow of North Atlantic Deep Water using chlorofluorocarbons, J. Geophys. Res., 105, 14,297-14,323, doi:10.1029/1999JC900274.

Smith, W. H. F., and P. Wessel (1990), Gridding with continuous curvature splines in tension, Geophysics, 55, 293-305.

Stommel, H. (1958), The abyssal circulation, Deep Sea Res., 5, 80-82.

Talley, L. D., and M. S. McCartney (1982), Distribution and circulation of Labrador Sea Water, J. Phys. Oceanogr., 12, 1189-1205.

Toole, J. M., et al. (2011), Transport of the North Atlantic Deep Western Boundary Current about $39^{\circ} \mathrm{N}, 70^{\circ} \mathrm{W}$ : 2004-2008, Deep Sea Res., Part II, 58, 1768-1780.

Vallis, G. K., and M. E. Maltrud (1993), Generation of mean flows and jets on a beta plane and over topography, J. Phys. Oceanogr., 23, 1346-1362. 